PREPARED FOR THE U.S. DEPARTMENT OF ENERGY, UNDER CONTRACT DE-AC02-76CH03073

PPPL-3487

PPPL-3487

UC-70

Short Wavelength Fluctuations and Electron Transport in TFTR

by

K.L. Wong, K. Itoh, S.-I. Itoh, A. Fukuyama, and M. Yagi

September 2000

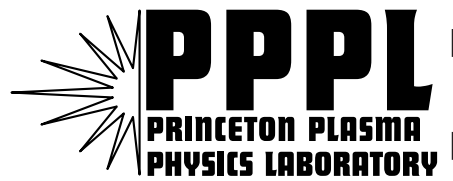

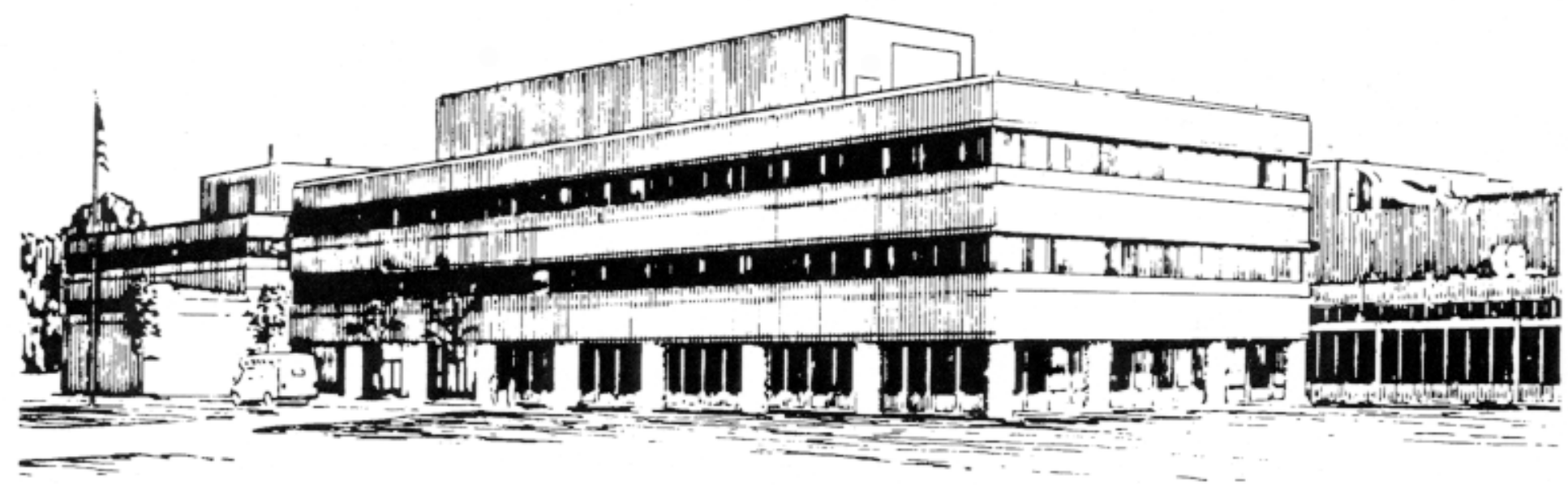

PRINCETON PLASMA PHYSICS LABORATORY PRINCETON UNIVERSITY, PRINCETON, NEW JERSEY 


\section{PPPL Reports Disclaimer}

This report was prepared as an account of work sponsored by an agency of the United States Government. Neither the United States Government nor any agency thereof, nor any of their employees, makes any warranty, express or implied, or assumes any legal liability or responsibility for the accuracy, completeness, or usefulness of any information, apparatus, product, or process disclosed, or represents that its use would not infringe privately owned rights. Reference herein to any specific commercial product, process, or service by trade name, trademark, manufacturer, or otherwise, does not necessarily constitute or imply its endorsement, recommendation, or favoring by the United States Government or any agency thereof. The views and opinions of authors expressed herein do not necessarily state or reflect those of the United States Government or any agency thereof.

\section{Availability}

This report is posted on the U.S. Department of Energy's Princeton Plasma Physics Laboratory Publications and Reports web site in Calendar Year 2000. The home page for PPPL Reports and Publications is: http://www.pppl.gov/pub_report/

DOE and DOE Contractors can obtain copies of this report from:

U.S. Department of Energy

Office of Scientific and Technical Information

DOE Technical Information Services (DTIS)

P.O. Box 62

Oak Ridge, TN 37831

Telephone: (865) 576-8401

Fax: (865) 576-5728

Email: reports@adonis.osti.gov

This report is available to the general public from:

National Technical Information Service

U.S. Department of Commerce

5285 Port Royal Road

Springfield, VA 22161

Telephone: $1-800-553-6847$ or

(703) $605-6000$

Fax: (703) 321-8547

Internet: http://www.ntis.gov/ordering.htm 


\title{
Short Wavelength Fluctuations and Electron Transport in TFTR
}

\author{
by \\ K.L. Wong ${ }^{1}$, K. Itoh ${ }^{2}$, S.-I. Itoh ${ }^{3}$, A. Fukuyama ${ }^{4}$, M. Yagi ${ }^{3}$ \\ ${ }^{1}$ Plasma Physics Laboratory, Princeton University, Princeton, New Jersey 08543, USA \\ ${ }^{2}$ National Institute for Fusion Science, Toki, Gifu, Japan \\ ${ }^{3}$ Kyushu University, Kyushu, Japan \\ ${ }^{4}$ Kyoto University, Kyoto, Japan
}

\begin{abstract}
Correlation between electron heat diffusivity and short wavelength $\left(\mathrm{k} \rho_{\mathrm{i}} \sim 5\right)$ fluctuation amplitude was observed in the TFTR tokamak in the core of ERS plasmas [1]. These fluctuations propagate in the ion diamagnetic drift direction with wave number comparable to $\omega_{\mathrm{pe}} / \mathrm{c}$. Further analysis of these data yields the ratios $\chi_{\mathrm{e}} / \chi_{\mathrm{i}}$ and $\chi_{\mathrm{e}} / \mathrm{D}_{\mathrm{e}}$, and their values are consistent with the picture that the electron transport is mainly induced by the short wavelength fluctuations in the plasma core where the long wavelength $\left(\mathrm{k} \rho_{\mathrm{i}} \sim 1\right)$ fluctuations are absent. Although there is not enough information to identify these short wavelength modes, the values of $\chi_{\mathrm{e}}$ is found to be comparable to theoretical predictions based on the current diffusive ballooning mode theory [2].
\end{abstract}

PACS: 52.25.Fi; 52.25.Gj; 52.35.Ra; 52.55.Pi 
Anomalous electron transport is a long-standing problem in magnetic plasma confinement devices. While major advances were made in the past decade in the control of ion transport by velocity shear [3], transport through the electron channel remains a mystery. During the final year of TFTR (Tokamak Fusion Test Reactor) operation, it was discovered that in the core of ERS (enhanced reversed shear) plasmas [4], variation of the local $\chi_{\mathrm{e}}$ during high power neutral beam injection correlates with the short wavelength $\left(\mathrm{k} \rho_{\mathrm{i}} \sim 5\right)$ fluctuation amplitude measured by microwave scattering [1]. These fluctuations propagate in the electron diamagnetic drift direction in the laboratory where the plasma is not stationary. After Doppler shift correction, they propagate in the ion diamagnetic drift direction in the plasma frame of reference. Preliminary results were published in 1997 [1]. The Doppler shift correction was based on a poloidal flow velocity calculated from neoclassical transport theory. Direct determination of the poloidal velocity [5] was performed later, and the initial measurements contradict neoclassical predictions in a variety of TFTR discharges. If these results were correct, it might have altered the propagation direction of these fluctuations in the plasma frame of reference. After many lengthy debates and detailed analysis, it was discovered that the gyromotion of the impurity ions and the finite life time of their energy states should be included in the data analysis of the rotation measurement [6]. With the atomic physics correction properly included, the measured poloidal flow velocity becomes consistent with neoclassical theory. This is still an on-going process; up to this point, no contradiction has been found between measurements and calculations, i.e., the previous published result [1] still stands. Further analysis of the TFTR data suggests that the short wavelength fluctuations play a role in electron transport in the core of ERS plasmas where the ion transport obeys neoclassical theory. These are very rare, high quality data obtained with the state-of-theart diagnostics, analyzed by the state-of-the-art analysis tools. Although the information 
at hand is not sufficient to identify these fluctuations, the results presented here constitute a small step towards the understanding of this very complicated problem.

The experiment was performed in TFTR in the enhanced confinement regime with the following parameters: $\mathrm{I}_{\mathrm{p}}=1.6 \mathrm{MA}, \mathrm{B}_{\mathrm{t}}=4.6 \mathrm{~T}$ at $\mathrm{R}=2.6 \mathrm{~m}, \mathrm{a}=0.94 \mathrm{~m}, \mathrm{~T}_{\mathrm{e}}(0) \leq$ $8 \mathrm{keV}, \mathrm{T}_{\mathrm{i}}(0) \leq 26 \mathrm{keV}$. Waveforms for various plasma parameters and data from microwave scattering were presented in an earlier paper [1]. High power neutral beam injection took place at $2.5 \mathrm{~s} \leq \mathrm{t} \leq 2.9 \mathrm{~s}$. Transport analysis by the TRANSP code yields the evolution of the electron heat diffusivity profile shown in Fig. 1. The changes in $\chi_{\mathrm{e}}$ after 3.0s were due to MHD activities associated with $\mathrm{q}_{\min }=2.0$. This is outside the scope of this paper. Our main interest here is in the rise of $\chi_{\mathrm{e}}$ in the plasma core immediately after the high power neutral beam injection. Since TRANSP is a very complicated computer code, it would be more convincing to demonstrate these features directly from the electron temperature profile. Figure 2a shows the raw electron cyclotron emission (ECE) data from a grating polychrometer. The calibration of this instrument has been carefully and repeatedly checked to ensure high data quality. Electron temperature in a tokamak is a flux function. After the plasma equilibrium is constructed, the electron temperature on various flux surfaces is plotted in Fig. 2b. TFTR plasmas have circular cross section, and the plasma minor radius is commonly used as the label for flux surfaces. At $t=2.60 \mathrm{~s}$, flat regions in $\mathrm{T}_{\mathrm{e}}(\mathrm{r})$ developed in the plasma core as well as in the neighborhood of $\mathrm{r} / \mathrm{a}=$ 0.4 which correspond to the same peak locations at $2.6 \mathrm{~s}$ in Fig. 1. From these data, one can see that although the sharp spikes in Fig. 1 are spurious, the rise in $\chi_{\mathrm{e}}$ around $2.6 \mathrm{~s}$ is evident from the changes in the spatial gradient of the $T_{e}$ profile.

In ERS plasmas, reflectometry measurements show that ITG-type (ion temperature gradient) fluctuations are absent in the plasma core $\left(r<r_{\min }\right)$ [7]. Due to orbit averaging effects, these short wavelength fluctuations can only influence electron 
transport, but not ion transport because $k \rho_{i} \gg>1$. Therefore, one would expect $\chi_{\mathrm{e}} / \chi_{\mathrm{i}} \gg 1$ for $r<r_{\text {min }}$. ITG-type fluctuations are present outside the plasma core [7]; they should have similar effects on the ions and the electrons in the strong turbulence limit because the two species have the same ExB drift velocity. Therefore, one would expect $\chi_{\mathrm{e}} / \chi_{\mathrm{i}} \sim 1$ for $r>r_{\min }$. These features are evident in the result depicted in Fig. 3a. Inside the plasma core, the plasma ion diffusivity $\mathrm{D}_{\mathrm{i}}$ is very small (near the neoclassical value). Due to charge quasi-neutrality, the electron diffusivity $\mathrm{D}_{\mathrm{e}}$ should also be very small. Therefore, $\chi_{\mathrm{e}} / \mathrm{D}_{\mathrm{e}}>>1$ is expected for $\mathrm{r}<\mathrm{r}_{\min }$. This feature is evident in Fig. 3b. All these results are consistent with fluctuation-induced plasma transport.

Electron transport in magnetic confinement devices is a very important and very complicated problem. The information at hand is not sufficient to identify these modes. The observed density fluctuations have $\mathrm{k} \sim \omega_{\mathrm{pe}} / \mathrm{c}$. In the plasma frame, these fluctuations propagate in the direction parallel to the ion diamagnetic drift with a frequency in the range of $(0.1-0.2) \omega_{*_{\mathrm{i}}}$ where $\omega_{*_{\mathrm{i}}}$ is the ion diamagnetic frequency. While we cannot rule out other possibilities here [8], the observed wave number, the mode frequency and the direction of propagation are quite similar to the current diffusive ballooning mode $(\mathrm{CDBM})[2]$. Therefore, we compare the measured $\chi_{\mathrm{e}}(\mathrm{r})$ with the predictions based on CDBM theory and find reasonable agreement in the plasma core $\left(r<r_{\min }\right)$. At $r=r_{\min }$, the magnetic shear vanishes, and the formula for $\chi_{\mathrm{e}}(\mathrm{IIF})$ no longer applies; this explains the large discrepancy between $\chi_{\mathrm{e}}(\mathrm{IIF})$ and $\chi_{\mathrm{e}}(\mathrm{TRANSP})$ at this location. At r/a $>0.6$, long wavelength fluctuations are expected to play a dominant role so that the measured $\chi_{\mathrm{e}}$ is higher than CDBM prediction. 
The TFTR experiment was carried with $\mathrm{k}_{\theta} \rho_{\mathrm{i}} \sim 5$. Justification is needed for the applicability of the formula of $\chi_{\mathrm{e}}$ in [2], which was derived in the absence of finiteLarmor-radius (FLR) effect of ions. The FLR effect on the CDBM turbulence has been studied recently [9]. This effect causes the coupling with drift waves. These fluctuations

propagate in the ion-diamagnetic drift direction for $\mathrm{k}_{\theta} \rho_{\mathrm{i}} \gg 1$, and the real frequency is of the order a few tenth of the ion-diamagnetic drift frequency. The FLR effect of ions tends to stabilize the linear ballooning mode. However, the nonlinear terms are also affected. The suppression by FLR effect primarily works for the ion transport, including the viscosity, so that the nonlinear stabilizing effect is also reduced. Nonlinear destabilization through turbulent current diffusivity is affected to a less extent. When all these effects are considered, the selective loss of electron energy remains in the presence of FLR effect, and the level of anomalous electron energy transport remains comparable to the case with $\mathrm{k}_{\theta} \rho_{\mathrm{i}} \ll<1$. Details of these theoretical analysis will be reported elsewhere [10].

Acknowledgements: This work is supported by The United States Department of Energy Contract DE-AC02-76CH03073, and partly by the Grant-in-Aid for Scientific Research of Ministry of Education, Science, Sports and Culture of Japan. 


\section{References}

[1] K.L. Wong, N.L. Bretz, T.S. Hahm, E. Synakowski, Phys. Lett. A 236 (1997) 339.

[2] K. Itoh, S.-I. Itoh, A. Fukuyama, M. Yagi, M. Azumi, Plasma Phys. Control. Fusion 36 (1994) 279.

[3] T.S. Hahm, K. H. Burrell, Phys. Plasmas 2 (1995) 1648.

[4] F.M. Levinton, M.C. Zarnstorff, et al., Phys. Rev. Lett. 75 (1995) 4417.

[5] R.E. Bell, L.E. Dudek, B. Grek, D.W. Johnson, R.W. Palladino, Rev. Sci. Instrum. 70 (1998) 821.

[6] R.E. Bell and E.J. Synakowski, PPPL-3447, Princeton Plasma Physics Laboratory, May 2000.

[7] E. Mazzucato et al., Phys. Rev. Lett. 77 (1996) 3145.

[8] W. Horton, B.G. Hong, W.M. Tang, Phys. Fluids 31 (1988) 2971.

[9] M. Uchida, A. Fukuyama, K. Itoh, S.-I. Itoh, M. Yagi, 1999 J. Plasma Fusion Res. SERIES, 2, p.117.

[10] M. Uchida, et al., paper in preparation. 


\section{Figure Captions}

Fig. 1 Evolution of $\chi_{\mathrm{e}}(\mathrm{r})$ from TRANSP analysis. High power neutral beam injection takes place from $2.5 \mathrm{~s}$ to $2.9 \mathrm{~s} . \chi_{\mathrm{e}}$ in the plasma core goes up immediately after the high power injection. It drops after ERS transition.

Fig. 2 The variations in $\chi_{\mathrm{e}}$ can be confirmed from the raw data of electron temperature profile. High $\chi_{\mathrm{e}}$ is associated with the flat temperature profile. (a) Raw ECE data of $T_{e}$ vs R. (b) Electron temperature profile after equilibrium construction with the Shafranov shift properly included.

Fig. 3 (a) Radial profile of $\chi_{\mathrm{e}} / \chi_{\mathrm{i}}$. (b) Radial profile of $\chi_{\mathrm{e}} / \mathrm{D}_{\mathrm{e}}$.

Fig.4 Comparison between experimentally determined $\chi_{\mathrm{e}}(\mathrm{r})$ analyzed by the TRANSP code and calculated values based on the CDBM theory [2]. 


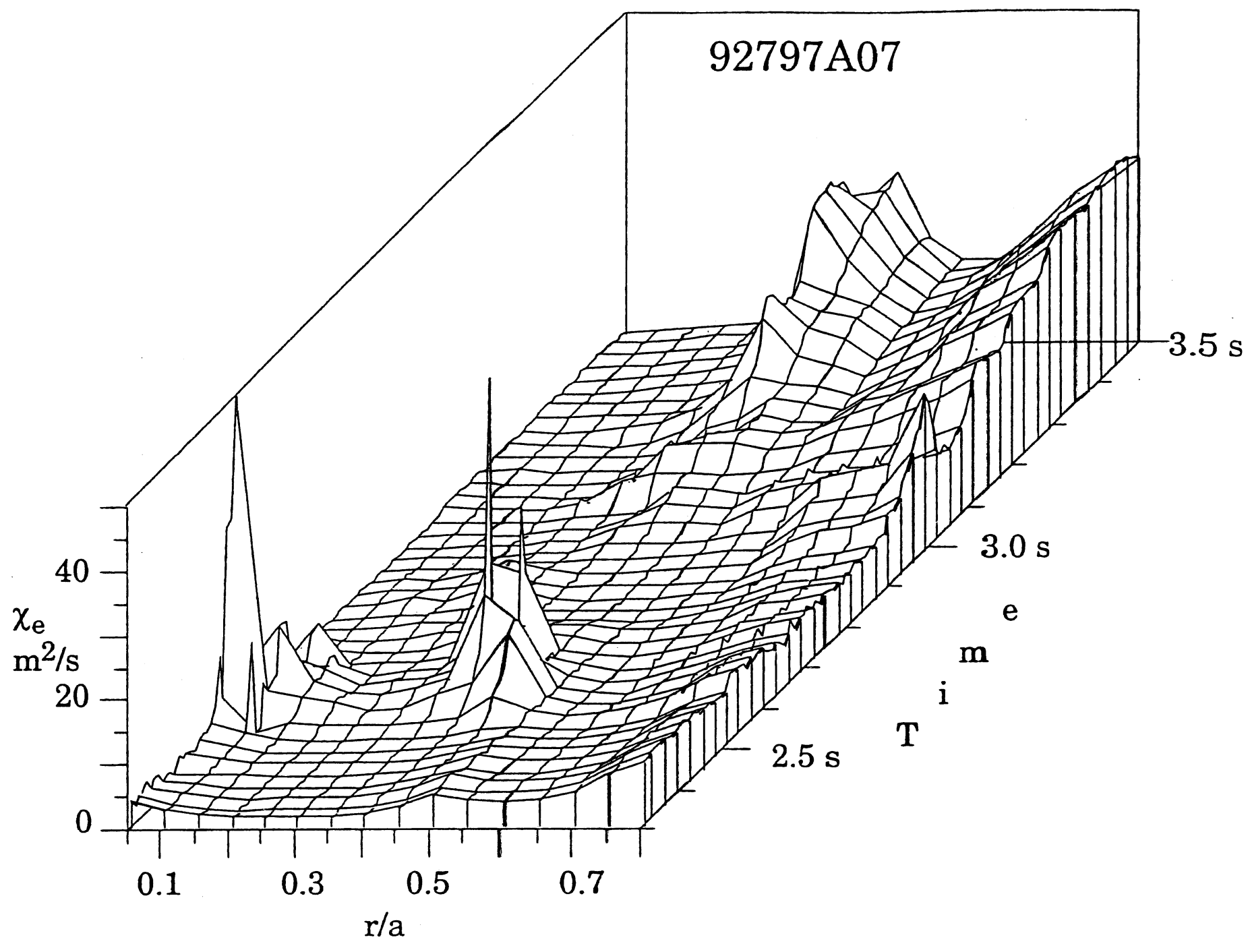

Figure 1. 

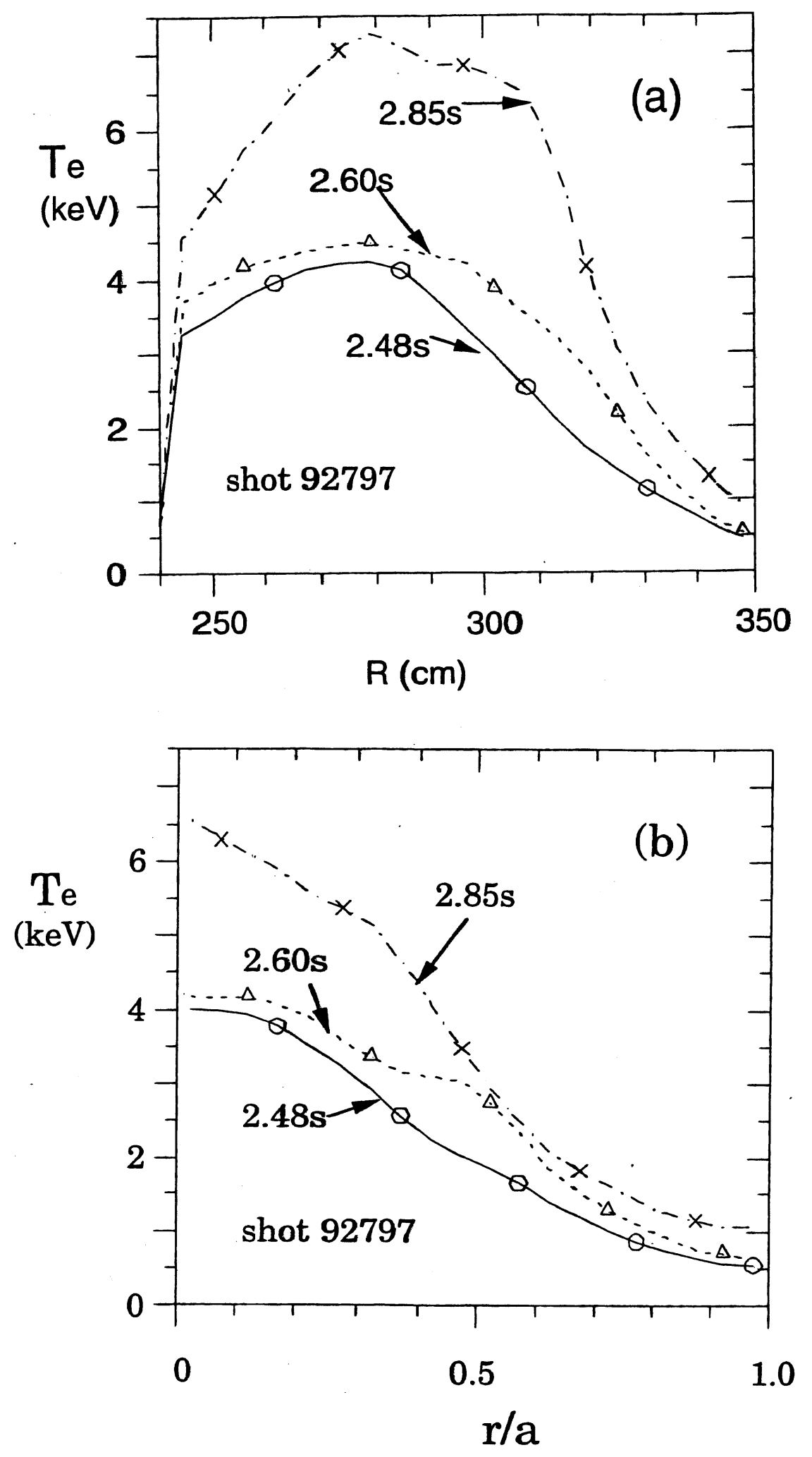

Figure 2. 

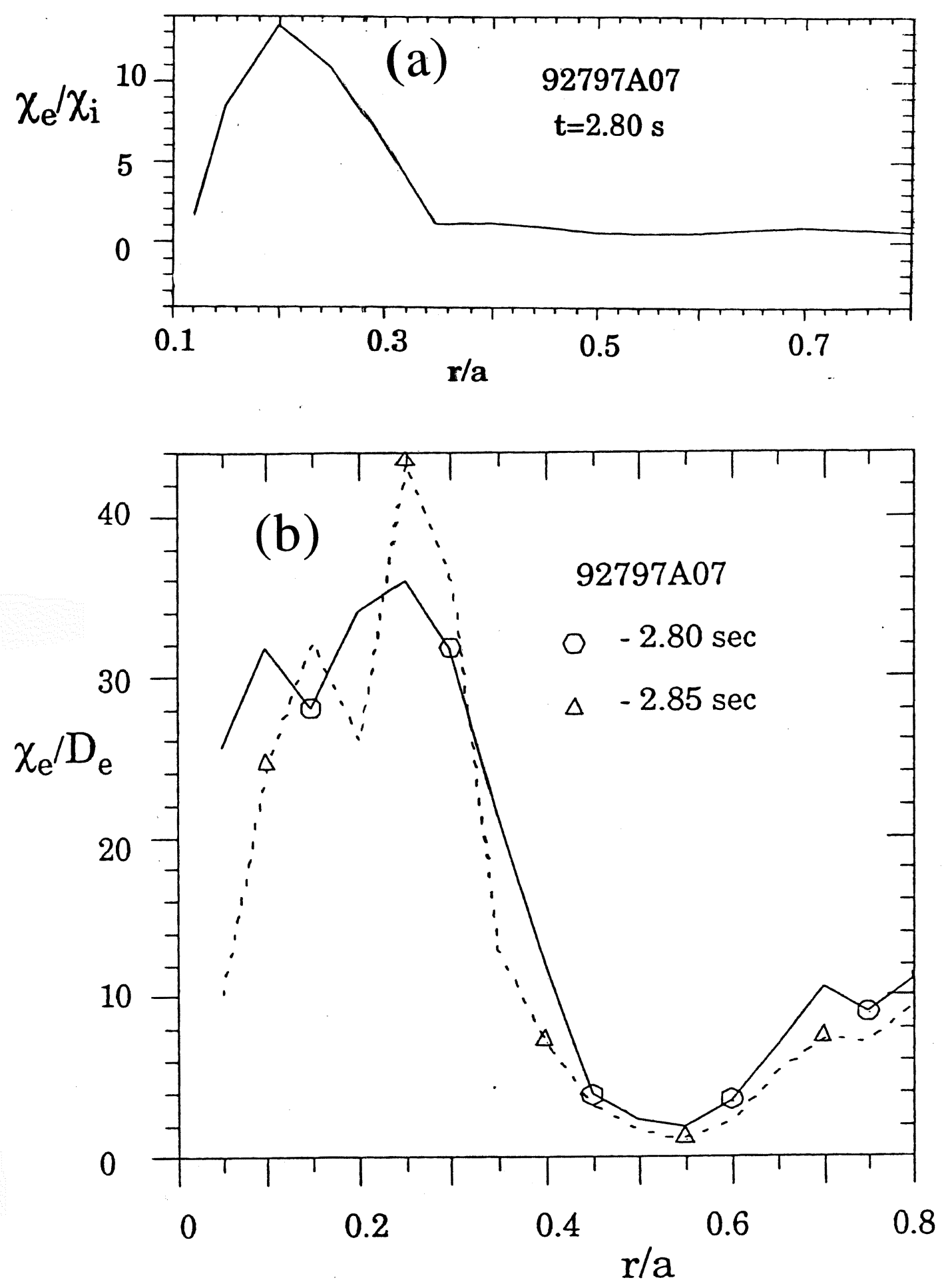

Figure 3. 


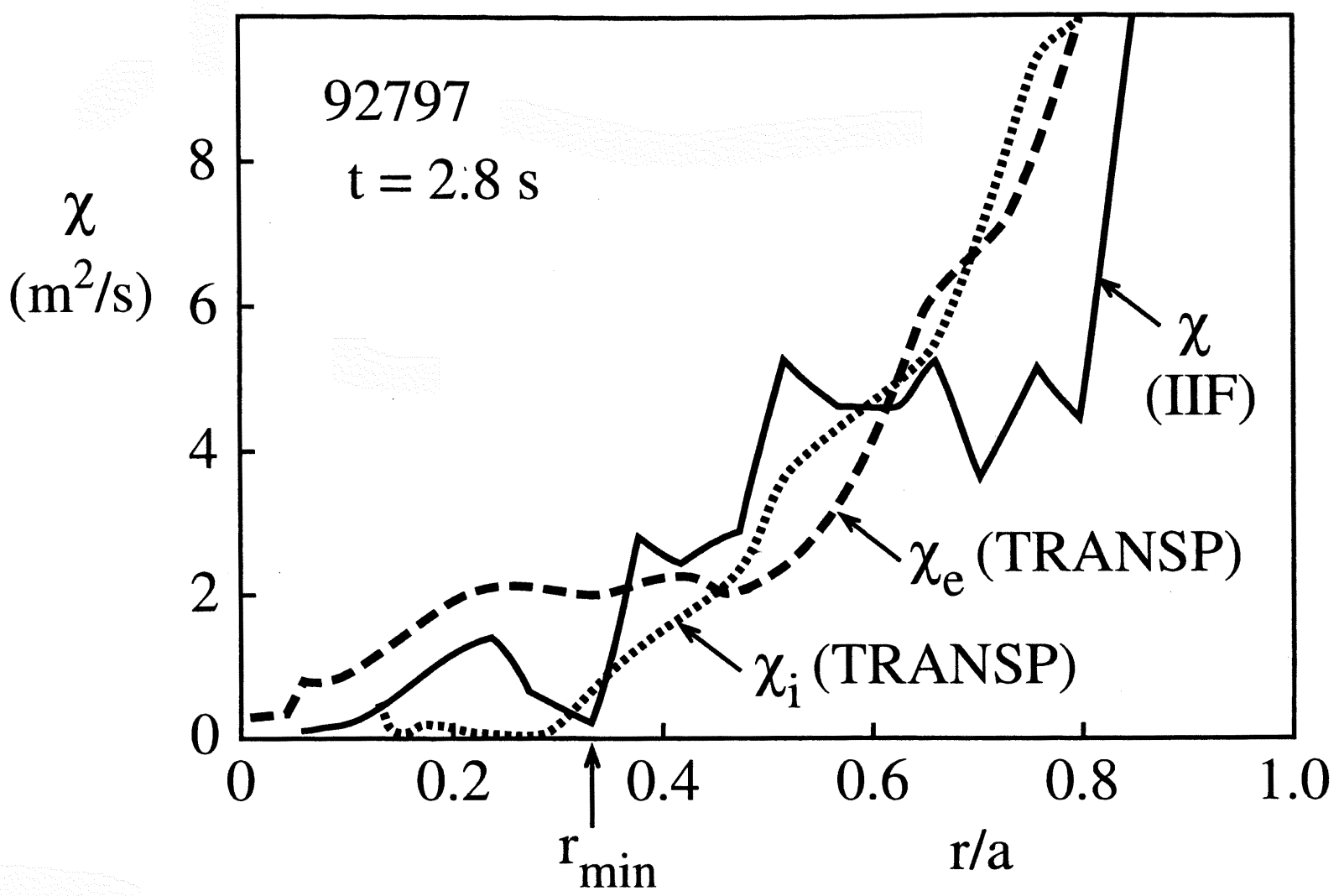

Figure 4. 
The Princeton Plasma Physics Laboratory is operated by Princeton University under contract with the U.S. Department of Energy.

\author{
Information Services \\ Princeton Plasma Physics Laboratory \\ P.O. Box 451 \\ Princeton, NJ 08543
}

Phone: 609-243-2750

Fax: 609-243-2751

e-mail: pppl_info@pppl.gov

Internet Address: http://www.pppl.gov 